Article

\title{
Enhancement of Material Properties of Lime-Activated Slag Mortar from Intensified Pozzolanic Reaction and Pore Filling Effect
}

\author{
Yang-Hee Kwon ${ }^{1}$, Sung-Hoon Kang ${ }^{2, *}$, Sung-Gul Hong ${ }^{2}{ }^{\mathbb{D}}$ and Juhyuk Moon ${ }^{3}$ \\ 1 Department of Traditional Architecture, Korea National University of Cultural Heritage, 367 Baekjemun-ro, \\ Gyuam-myeon, Buyeo-gun, Chungcheongnam-do 33115, Korea; yanga1126@nuch.ac.kr \\ 2 Department of Architecture \& Architectural Engineering, Seoul National University, 1 Gwanak-ro, \\ Gwanak-gu, Seoul 08826, Korea; sglhong@snu.ac.kr \\ 3 Department of Civil and Environmental Engineering, Seoul National University, 1 Gwanak-ro, Gwanak-gu, \\ Seoul 08826, Korea; juhyukmoon@snu.ac.kr \\ * Correspondence: medesis@snu.ac.kr; Tel.: +82-2-880-7366
}

Received: 23 October 2018; Accepted: 16 November 2018; Published: 20 November 2018

\begin{abstract}
To utilize alkali-activated materials widely, this study investigates the effects of an intensified pozzolanic reaction and pore filling by silica fume on various material properties of lime-activated slag mortar. Although ground-granulated blast-furnace slag is classified as a cementitious material, it commonly requires an activator to enhance the performance of structural materials. In the first step of the improvement strategy, slag reaction is activated by hydrated lime. Next, silica fume is added to densify the microstructure by the physical pore filling effect and/or the pozzolanic reaction that additionally forms hydration products. This increased the compressive strength by $18 \%$ at 28 days and by $25 \%$ at 91 days under ambient curing condition, mainly due to the physical effect. Moreover, elevated temperature curing for three days was highly effective to further improve the strength, and to accelerate strength development. This is because both the physical effect and the chemical reaction are effective at the high temperature curing condition. The conducted microstructural investigation provided the evidence for the intensified pozzolanic reaction and pore filling effect, both of which are closely related to the mechanical properties. It is also found that the use of silica fume positively contributes to the dimensional stability. Since the developed material exhibits high strength (>40 MPa after 14 days) without Portland cement or highly toxic chemicals, it can be practically used as an eco-friendly structural mortar.
\end{abstract}

Keywords: alkali-activated material; slag mortar; pozzolanic reaction; pore filling effect; ground-granulated blast-furnace slag; silica fume

\section{Introduction}

On 6 October 2018, the intergovernmental panel on climate change approved the report stating that lowering the upper limit of global warming from below $2.0^{\circ} \mathrm{C}$ to below $1.5^{\circ} \mathrm{C}$ would help all life on earth to survive, including humans [1]. According to the report, the global temperature is already about $1{ }^{\circ} \mathrm{C}$ higher than the pre-industrial one, and global $\mathrm{CO}_{2}$ emissions must be reduced by $45 \%$ by 2030, as compared to 2010, and the emissions must be zero by 2050, to limit the temperature rising to within $0.5^{\circ} \mathrm{C}$. In this regard, policies and requirements for reducing greenhouse gas emissions are expected to be enhanced across all industries. In the construction industry, research and development on alternative binders to Portland cement (PC) have been conducted for decades [2] to reduce the demand for $\mathrm{PC}$, which accounts for about $8 \%$ of global $\mathrm{CO}_{2}$ emissions during its production $[3,4]$. Nevertheless, the demand is steadily increasing [5-7]. As an effort to mitigate global warming, 
eco-friendly construction materials should be more widely used. Consequently, practical studies on improving mechanical properties and durability of the materials have become more important than ever before.

One way to reduce $\mathrm{CO}_{2}$ emissions is to extensively use alkali-activated materials, which are composed of an aluminosilicate precursor, such as fly-ash, metakaolin, or ground-granulated blast-furnace slag (GGBFS), and an alkaline activator [8-10]. In particular, GGBFS is one of the most suitable precursors in terms of practicality and mechanical performance of the materials [11,12]. In addition, alkali-activated slag composites show lower hydration heat and better durability compared to PC-based composites [13,14]. However, conventional activators-such as solutions containing sodium (or potassium) hydroxide and/or sodium silicate [15,16] — have shown limitations in terms of workability due to rapid setting and high $\mathrm{pH}$ (or toxicity), price competitiveness due to high-purity chemicals, and long-term properties due to a significant amount of shrinkage and salt efflorescence formation $[17,18]$. As a remedy, lime activation on the slag has been suggested because of its workability, durability, and price competitiveness $[18,19]$. However, this method has also shown some limitations in terms of mechanical performance and strength development, especially when practical conditions are reflected; for instance, compressive strength was decreased with increasing aggregate-to-binder ratio or decreasing curing relative humidity (RH) [19-21]. In addition, shrinkage characteristics of the lime-activated slag (LAS) composites, under various curing conditions, are not fully understood. This can also be a factor that hinders its practical utilization [2,22].

In order to use LAS composites practically, the materials should be able to be used as structural elements, as in PC mortar or concrete. To this end, the materials should possess sufficient mechanical properties, strength development, and dimensional stability. One promising method to achieve this, without using PC or strong alkali activators, is to include a reactive pozzolan, such as silica fume (SF), so that more calcium hydroxide $\left(\mathrm{Ca}(\mathrm{OH})_{2}\right)$ in the composites can participate in the pozzolanic reaction. Especially, the reaction by SF is significantly accelerated at an elevated temperature condition [23,24]. As a hexagonal shaped crystal, with a low surface area in the LAS, $\mathrm{Ca}(\mathrm{OH})_{2}$ can be consumed in the formation of calcium-silicate-hydrate with chemically strong connections; thereby, the weak part of the composites decreases and the microstructure becomes dense [25]. This, in turn, can contribute greatly to improving mechanical performance and durability. In addition, the SF, which is composed of nanoparticles, if not reacted, can physically fill the capillary pores, by the pore filling effect $[26,27]$. In summary, the addition of SF to the LAS composites can improve their mechanical performance and durability through physical and chemical means.

To develop a practically usable GGFBS-based structural mortar, this study investigated the physical and chemical contributions of SF addition on the mechanical performance and dimensional stability of the mortar. For this, various experiments on hydration reaction, microstructure, materials properties, and dimensional stability were performed. In addition, since the developed materials can be utilized in various ways, such as precasting or in situ casting, the effect of initial elevated temperature curing on the mortar with or without SF was investigated.

\section{Experimental}

\subsection{Materials}

The GGBFS was obtained from the Dangin steel manufacturing company in Korea. The hydrated lime (HL) and SF (Grade 940U, Elkem, Norway) used are commercially available industrial products, not high-purity (or expensive) chemicals. Fine aggregate that satisfies ISO standards were adopted for reproducibility of the test results [28]. In addition, a polycarboxylate-ether type superplasticizer (Flowmix 3000S, Dongnam, Korea) was used for the workability of the mortar. The chemical composition and morphology analysis of the raw materials are presented in Table 1 and Figure 1 , respectively. These were determined using X-ray fluorescence analysis (XRF-1700, Shimadzu, Japan) and a scanning electron microscope (SEM) (JSM-7800F Prime, JEOL, Japan), respectively. The slag is 
mainly (84.5 wt \%) composed of silica $\left(\mathrm{SiO}_{2}\right)$, alumina $\left(\mathrm{Al}_{2} \mathrm{O}_{3}\right)$, and calcium oxide $(\mathrm{CaO})$ components, while the $\mathrm{HL}$ is composed mainly $(74.5 \mathrm{wt} \%)$ of $\mathrm{CaO}$ components, induced from $\mathrm{Ca}(\mathrm{OH})_{2}$ and calcium carbonate $\left(\mathrm{CaCO}_{3}\right)$. SF has a bulk density of $200-350 \mathrm{~kg} / \mathrm{m}^{3}$ based on the manufacturer's material data sheet, and specific surface area of $15-30 \mathrm{~m}^{2} / \mathrm{g}$ based on the previous measurements [29]; it contains mainly silica ( $97 \mathrm{wt} \%$ ), as shown in Table 1 . In addition, Figure 1 shows the irregular shaped GGBFS particles, the plate-shaped $\mathrm{Ca}(\mathrm{OH})_{2}$ in $\mathrm{HL}$ particles, and the perfectly globular SF particles. The particle size distributions of the materials are presented in Figure 2, in terms of percentage volume density. These were determined by a laser diffraction method using Mastersizer 3000 (Malvern Instruments, Malvern, UK) for GGBFS and HL, and by an image-processing method for SF $[26,27]$. The laser diffraction method also provided a specific surface area of GGBFS $\left(6.9 \mathrm{~m}^{2} / \mathrm{g}\right)$ and HL $\left(1.3 \mathrm{~m}^{2} / \mathrm{g}\right)$. The particles sizes of GGBFS and HL range within 1-100 $\mu \mathrm{m}$, while the SF size ranges between $30-500 \mathrm{~nm}$. Thus, it is expected that the nano particles can effectively fill the void between the micro particles.

Table 1. Chemical compositions of used raw materials (wt \%).

\begin{tabular}{cccccccccccccc}
\hline Materials & $\mathrm{SiO}_{2}$ & $\mathbf{A l}_{2} \mathbf{O}_{3}$ & $\mathrm{Fe}_{2} \mathbf{O}_{3}$ & $\mathbf{C a O}$ & $\mathbf{K}_{\mathbf{2}} \mathbf{O}$ & $\mathbf{N a}_{\mathbf{2}} \mathbf{O}$ & $\mathbf{M g O}$ & $\mathbf{P}_{\mathbf{2}} \mathbf{O}_{5}$ & $\mathbf{T i O}_{2}$ & $\mathbf{M n O}$ & $\mathbf{S O}_{3}$ & LOI $^{\mathbf{1}}$ & Total \\
\hline GGBFS & 30.8 & 14.4 & 0.5 & 39.3 & 0.4 & - & 8.6 & - & 0.8 & 0.8 & 3.0 & 1.3 & 99.9 \\
Hydrated lime & 0.6 & 0.5 & 0.1 & 74.5 & 0.1 & - & 1.1 & - & - & - & - & 23.0 & 100.0 \\
Silica fume & 97.0 & 0.7 & 0.1 & 0.3 & 0.8 & 0.3 & 0.4 & 0.1 & - & - & 0.2 & 0.0 & 99.9 \\
\hline
\end{tabular}

${ }^{1}$ Loss on ignition. GGBFS, ground-granulated blast-furnace slag.
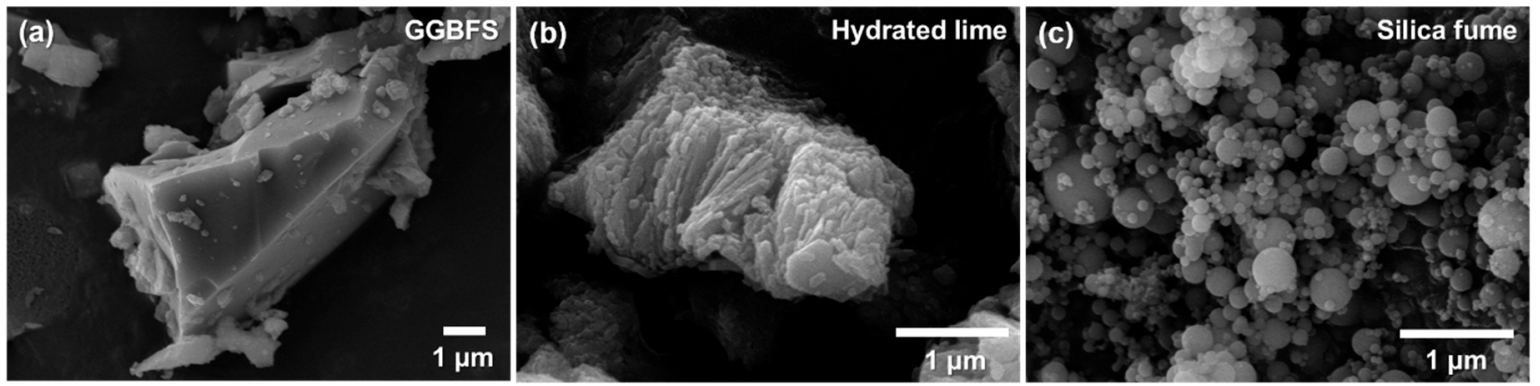

Figure 1. Microscope images of raw materials: (a) GGBFS, (b) hydrated lime, and (c) silica fume.

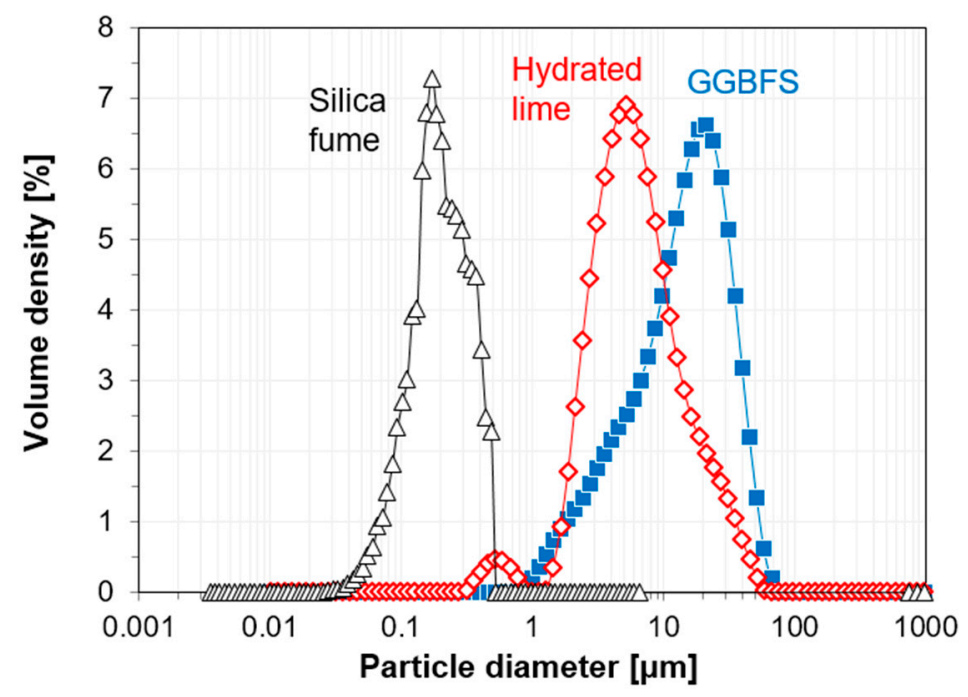

Figure 2. Particle size distributions of raw materials measured by image-processing method for silica fume, and laser diffraction method for GGBFS and hydrated lime. 


\subsection{Sample Preparation}

The mix proportions and sample names of the slag mortars are shown in Table 2. Here, alkaliactivated slag, composed of GGBFS and HL (i.e., aluminosilicate and precursor), is considered a cementing material. In the sample name, REF and REF + SF can be distinguished by the inclusion of $\mathrm{SF}$ (15 wt \% of cementing materials), and the weight ratio of fine aggregate to the cementing materials was three in all the samples. This means that at least $2 / 3$ of the mortar developed consists of aggregate. In addition, two samples of REF and REF + SF are divided into four samples again, depending on the curing program. For instance, $\operatorname{REF}(\mathrm{A})$ is cured under an ambient curing condition $\left(20^{\circ} \mathrm{C}\right.$ and $\left.\mathrm{RH} 60 \%\right)$ until the test day, whereas $\mathrm{REF}(\mathrm{E})$ is subjected to an elevated temperature curing $\left(60^{\circ} \mathrm{C}\right.$ and $\left.\mathrm{RH}>95 \%\right)$ for the first three days, followed by ambient curing until the test day.

Table 2. Mix proportions of the lime-activated slag mortars (by weight ratio of cementing materials).

\begin{tabular}{|c|c|c|c|c|c|c|}
\hline Sample Name & Curing Program ${ }^{1}$ & $\begin{array}{c}\text { Cementing Materials } \\
\text { (GGBFS:Hydrated Lime) }\end{array}$ & $\begin{array}{l}\text { Silica } \\
\text { Fume }\end{array}$ & $\begin{array}{c}\text { Fine } \\
\text { Aggregate }\end{array}$ & Water & $\begin{array}{c}\text { Super- } \\
\text { Plasticizer }\end{array}$ \\
\hline $\begin{array}{c}\mathrm{REF}(\mathrm{A}) \\
\mathrm{REF}+\mathrm{SF}(\mathrm{A})\end{array}$ & Ambient curing & \multirow{2}{*}{$1(0.7: 0.3)$} & $\begin{array}{c}- \\
0.15\end{array}$ & \multirow[b]{2}{*}{3} & \multirow[b]{2}{*}{0.27} & \multirow[b]{2}{*}{0.009} \\
\hline $\begin{array}{c}\mathrm{REF}(\mathrm{E}) \\
\mathrm{REF}+\mathrm{SF}(\mathrm{E})\end{array}$ & $\begin{array}{l}\text { Elevated temperature curing } \\
\text { followed by ambient curing }\end{array}$ & & $\begin{array}{c}- \\
0.15\end{array}$ & & & \\
\hline
\end{tabular}

The mortars samples were prepared according to the ASTM standard [30], and cured in a programmed chamber. The seal of the sample was removed after one day unless the elevated temperature curing was subjected to the sample, while the seal was removed after three days in the case of the elevated temperature curing. Meanwhile, paste samples, which do not include aggregate, were additionally prepared for the experiments on the hydration reaction and microstructure, such as isothermal calorimetry and X-ray diffraction (XRD) analysis.

\subsection{Test Method}

\subsubsection{Mechanical Properties}

Mechanical properties, such as compressive strength, elastic modulus, and flexural strength tests were performed on the slag mortars. Each property on the test day was determined based on the average of the three measurements. To measure the compressive strength, the cubic specimens $(50 \mathrm{~mm} \times 50 \mathrm{~mm} \times 50 \mathrm{~mm}$ ) were loaded at $1,3,7,14,28,56$, and 91 days using a hydraulic universal testing machine, according to ASTM C109 [31]. The flexural strength of the prismatic specimens $(40 \mathrm{~mm} \times 40 \mathrm{~mm} \times 160 \mathrm{~mm})$ was measured at 91 days, according to ISO 679 [28]. On the same day, the elastic modulus was determined by using two strain gauges attached to the surface of the cylindrical specimen ( $\Phi 50 \mathrm{~mm} \times 100 \mathrm{~mm}$ ), longitudinally. Before loading the specimen, the dimension (diameter and height) and weight of the cylinder were measured using a digital Vernier caliper $(0.02 \mathrm{~mm}$ of accuracy) and an electronic scale (Entris 623i-1S, Sartorius, Germany), respectively. The results were used for calculating the bulk density of the mortar samples.

\subsubsection{Hydration Reaction and Porosity Analysis}

The hydration heat emitted from $15 \mathrm{~g}$ of paste was measured using an isothermal calorimeter (TAM AIR, TA Instruments, New Castle, DE, USA) for the first three days; here, as presented in Table 2, the different curing temperatures were subjected to the samples, following previous studies [24,32]. The measured heat flow and cumulative heat were normalized by the weight of the cementing materials in each paste sample. 
XRD analysis was performed to examine the mineralogical characteristics of the raw materials and hydrated samples. For the latter case, the pastes samples cured for 28 days were crushed and grounded into powder form. The prepared powders were placed in a holder of the analyzer (Miniflex,

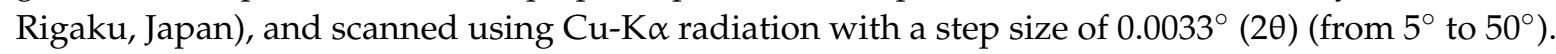
The crystalline phases were identified by comparing the Bragg peak positions and the intensities from the inorganic crystal structure database (ICSD) [33].

Mercury intrusion porosimetry (MIP) was used to investigate the pore structure of the mortar samples. The mortars cured for 91 days were cut into small cubes ( $5 \mathrm{~mm}$ length on one side), and their pore size distributions were measured using AutoPore IV 9500 (Micromeritics, Norcross, GA, USA). The set mercury parameters were $400 \mathrm{MPa}, 485 \mathrm{erg} / \mathrm{cm}^{2}$ and $130^{\circ}$ for the maximum pressure, surface tension, and contact angle, respectively.

\subsubsection{Shrinkage and Weight Loss}

Shrinkage behavior of the mortars was examined for 91 days, following the method of the previous studies [32,34]. For this, a dumbbell-shaped strain gauge (PMF series, Tokyo Sokki Kenkyujo Co., Ltd., Tokyo, Japan) was embedded in the center of the specimen $(40 \mathrm{~mm} \times 40 \mathrm{~mm} \times 160 \mathrm{~mm}$ ) longitudinally, and connected to a data logger (TDS-530, Tokyo Sokki Kenkyujo Co., Ltd.). The free strain was recorded every $5 \mathrm{~min}$, after $10 \mathrm{~min}$ of casting, unless elevated temperature curing was applied to the mortars. In the case of elevated temperature curing, the recording started once the curing temperature decreased to $20^{\circ} \mathrm{C}$.

To measure the autogenous shrinkage, the evaporation of the mortar specimens was prevented using adhesive aluminum tape right after demolding, while the total shrinkage was measured using the specimens exposed to the dry air $\left(20^{\circ} \mathrm{C}\right.$ and $\left.\mathrm{RH} 60 \%\right)$. The drying shrinkage was determined by subtracting the autogenous shrinkage from the total shrinkage [32,35]. In addition, using the same size of specimens $(40 \mathrm{~mm} \times 40 \mathrm{~mm} \times 160 \mathrm{~mm})$, the weight changes were measured during the same period, with a time interval of one day.

\section{Results and Discussion}

\subsection{Mechanical Properties}

The compressive strength of LAS mortars is presented in Figure 3. The red and blue lines indicate the strength development of the mortar with or without elevated temperature curing, respectively. Regardless of the curing conditions, the SF addition was highly effective in enhancing the strength (circular mark) of the mortar. In this case, the strength development between one and three days was especially pronounced. As a result, the mortars with SF showed $>30 \mathrm{MPa}$ after seven days, and $>40 \mathrm{MPa}$ after 14 days. This is comparable to that of a normal PC concrete or mortar, and it is remarkably higher (by 65-84\%) than pervious wet-cured LAS composites on the basis of 28 days strength $[18,19]$. However, the strength of the mortars without SF (square marks) was considerably lower (as much as 10-30 MPa) than those with SF (circular marks) after 14 days.

The elevated temperature curing was significantly effective not only to improve the compressive strength, but to accelerate strength development. For this reason, the LAS + SF(E) exhibited about $60 \mathrm{MPa}$ after three days, in contrast to LAS + SF(A) showing $52 \mathrm{MPa}$ at 91 days. The intensified pozzolanic reaction at $60^{\circ} \mathrm{C}$ and the physical pore filling effect by SF could result in these improvements. The causes can be identified in the next section, based on the obtained evidence from the microstructural analysis. However, this curing method was not effective unless the reactive pozzolan, SF, was included; that is, the sample with elevated temperature curing (LAS(E)) showed an almost similar strength development to the sample without the curing (LAS(A)). This implies that, despite the elevated temperature curing, the pozzolanic reaction was not promoted without the presence of SF. 


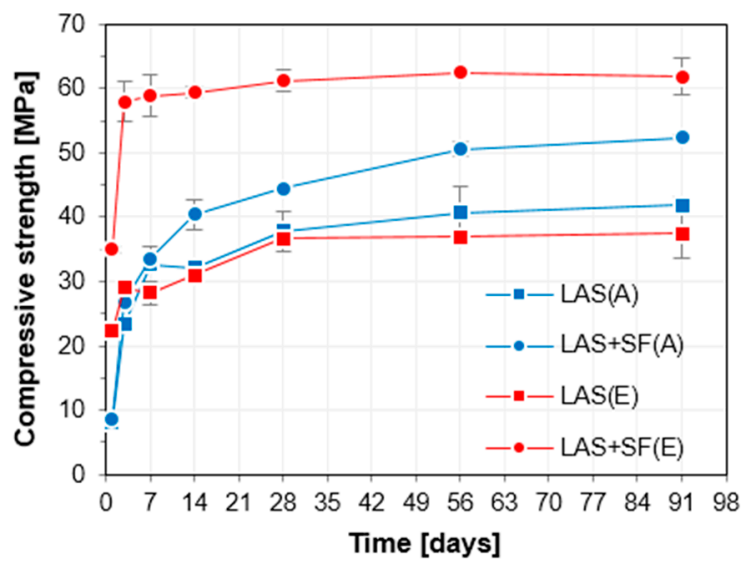

Figure 3. Compressive strength development of slag mortars.

Figure $4 a, b$ show various materials properties of the slag mortars, such as flexural strength, elastic modulus, and bulk density. Unlike compressive strength, the flexural strength did not vary depending on the curing temperature except when the SF was included without elevated temperature curing (Figure 4a). On the other hand, the addition of SF significantly contributed to the increase in the elastic modulus and the density, irrespective of curing conditions (Figure $4 \mathrm{~b}$ ). That is, the elastic modulus increased by $26-34 \%$, and the density also increased by the same trend. Based on the test results in this study, the SF addition was more effective in enhancing the materials properties than the elevated temperature curing. Regarding the elastic modulus, although the highest data was obtained when both methods were applied together to the slag mortar (i.e., sample LAS + SF(E)), an almost similar result was shown in the ambient-cured mortar (i.e., sample LAS + SF(A)). This contrasts with the result of compressive strength in Figure 3, which shows a considerable difference at 91 days. Therefore, it can be concluded that elevated temperature curing of slag mortar with SF significantly improves its post-elastic behavior, which means the behavior after $40 \%$ of the maximum load in the stress-strain curve.
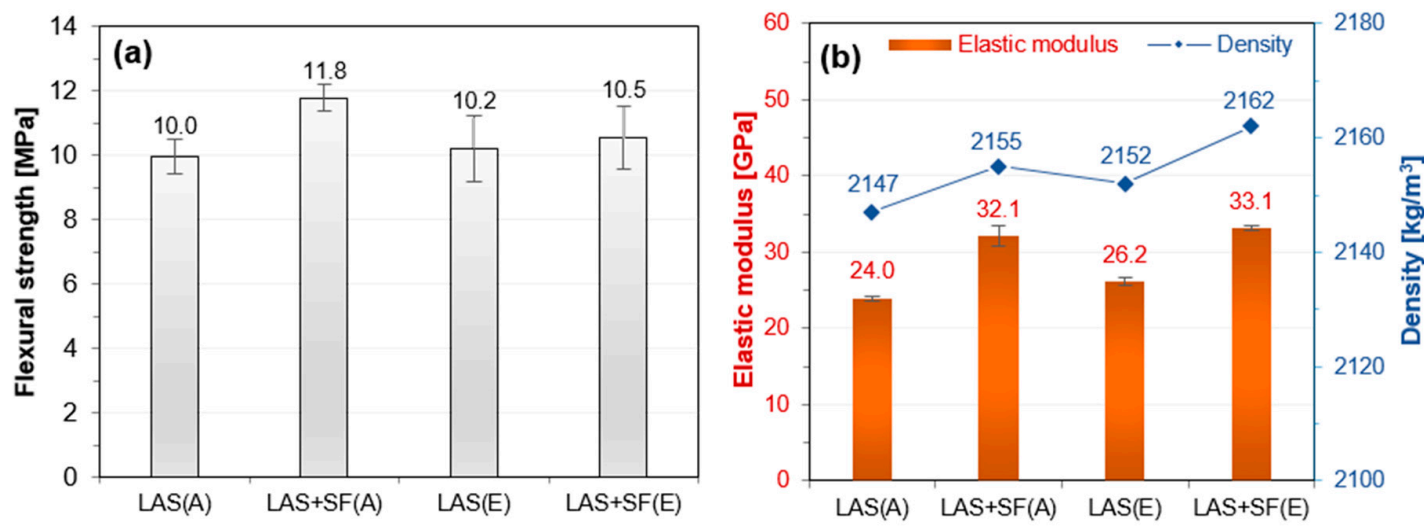

Figure 4. Material properties of slag mortars at 91 days: (a) Flexural strength and (b) elastic modulus and density.

\subsection{Hydration Reaction and Microstructure}

\subsubsection{Isothermal Calorimetry}

The heat flow and cumulative heat of the paste samples are presented in Figure 5a,b, respectively. All samples showed a single hydration peak in their heat flow curves for three days (Figure 5a). As curing temperature rose from 20 to $60^{\circ} \mathrm{C}$, the maximum heat flow (height of the main hydration peak) significantly increased, and its formation timing accelerated from $12-15 \mathrm{~h}$ to $2-3 \mathrm{~h}$. However, at $20^{\circ} \mathrm{C}$, the addition of the $\mathrm{SF}$ delayed the formation timing by $2.6 \mathrm{~h}$ (from 12.4 to $15 \mathrm{~h}$ ) without any 
increase in the peak height; after which, it did not influence the heat emissions. This resulted in lower cumulative heat, as shown in Figure 5b (compare two blue lines). In the PC-based composites with a low water-to-binder ratio $(\mathrm{w} / \mathrm{b})$, an ultrafine particle layer on the surface of the cement particle is formed due to the addition of SF (100,000 SF particles per one cement particle), and it delays the cement hydration by disturbing water diffusion into cement particles [36-38]. This would be valid in the slag composites with low $\mathrm{w} / \mathrm{b}$, as is the case in this study. On the other hand, at $60^{\circ} \mathrm{C}$, the addition of SF accelerated the formation timing of the peak by $0.5 \mathrm{~h}$ (from 2.7 to $2.2 \mathrm{~h}$ ), as shown in Figure $5 \mathrm{a}$ (compare two red lines). Although the maximum heat flow was slightly reduced before $6 \mathrm{~h}$, it significantly promoted heat flow after $6 \mathrm{~h}$. As a result, the cumulative heat after $12 \mathrm{~h}$ was considerably higher in the sample with SF than without it (Figure 5b).
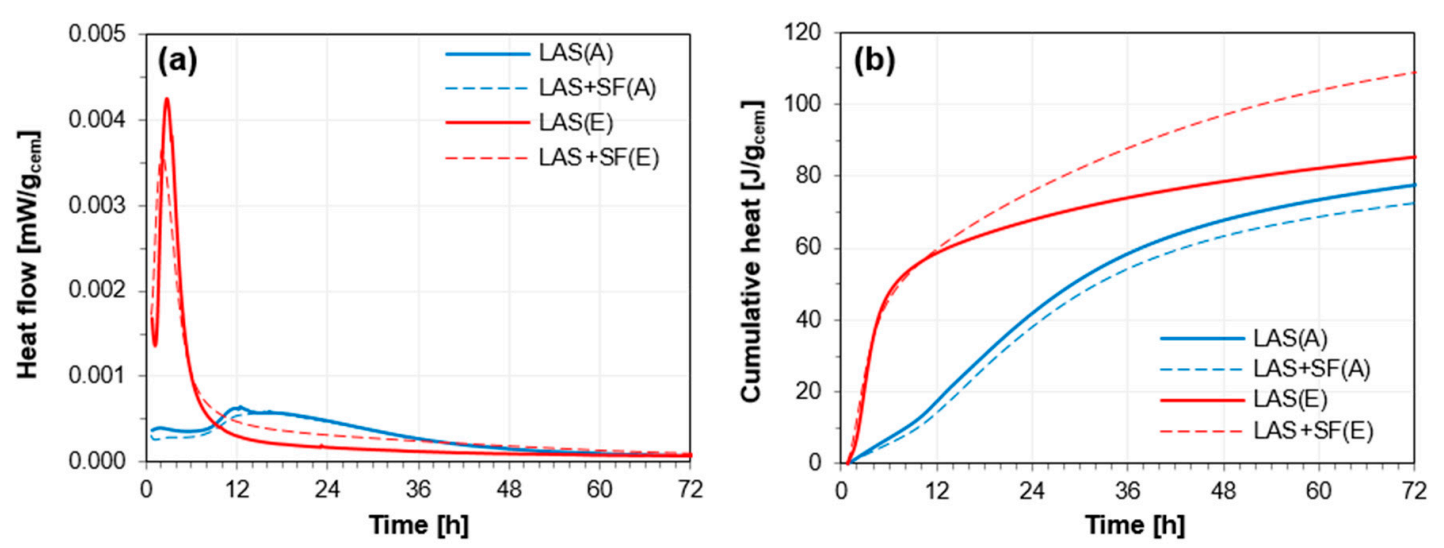

Figure 5. Heat of hydration reaction: (a) Heat flow and (b) cumulative heat.

\subsubsection{XRD Analysis}

Figure 6 shows the collected XRD patterns of the raw materials and the hydrated pastes. Above all, it is confirmed that SF and HL are mostly composed of amorphous silica (97 wt \%), and crystals, such as portlandite (mineral name of $\mathrm{Ca}(\mathrm{OH})_{2}$ ) and calcite (mineral name of $\mathrm{CaCO}_{3}$ ), respectively. GGBFS contained both amorphous phases and crystals, such as anhydrite, quartz, and merwinite. These crystals, included in the slag, were also detected in all hydrated samples (refer to black-dashed lines in Figure 6), indicating these were not newly generated hydration products. Similarly, portlandite and calcite peaks were also detected in the hydrated samples (green-dashed lines). These should come from the raw material (i.e., HL) if there was no carbonation. However, the calcite peak formed at about $23^{\circ}(2 \theta)$ implies that there was a carbonation reaction during sample curing or preparation process. Moreover, all hydrated samples showed the formation of ettringite and hydrotalcite as newly generated crystals. Among them, the former is attributed to the anhydrite in GGBFS [11], and hydrotalcite is observed as hydration product of LAS composites, due to the magnesium component in the slag [18].

An interesting result is observed when looking at the portlandite peaks in the XRD patterns: They were enlarged in the figure. Except for the sample with SF and the elevated temperature curing (i.e., sample LAS $+\mathrm{SF}(\mathrm{E})$ ), the size of the portlandite peaks in the other samples was almost identical. On the other hand, the peak size of LAS + SF(E) is remarkably small. This finding suggests that not much additional pozzolanic reaction, despite the SF addition, took place under the ambient curing conditions up to 28 days, as also indicated in the heat flow curves in Figure 5. In other words, a further pozzolanic reaction by the SF addition was valid only under elevated temperature $\left(60^{\circ} \mathrm{C}\right)$. This coincides with the hydration heat test presented in Figure 5, and, thus, suggests that the intensified pozzolanic reaction was effective after $6 \mathrm{~h}$. Owing to its high specific surface area, the amorphous silica in SF can be effectively supplied to facilitate the consumption reaction of $\mathrm{Ca}(\mathrm{OH})_{2}$ at an elevated temperature $[39,40]$. For this reason, the compressive strength and its development were especially pronounced in the sample LAS $+\mathrm{SF}(\mathrm{E})$. Meanwhile, although there was no additional hydration reaction (Figure 5) or $\mathrm{Ca}(\mathrm{OH})_{2}$ consumption (Figure 6), the material properties of the ambient-cured 
mortars were significantly improved by the SF addition, as mentioned in Section 3.1. In this case, therefore, the pore filling effect rather than the intensified pozzolanic reaction might have contributed to the improvements.

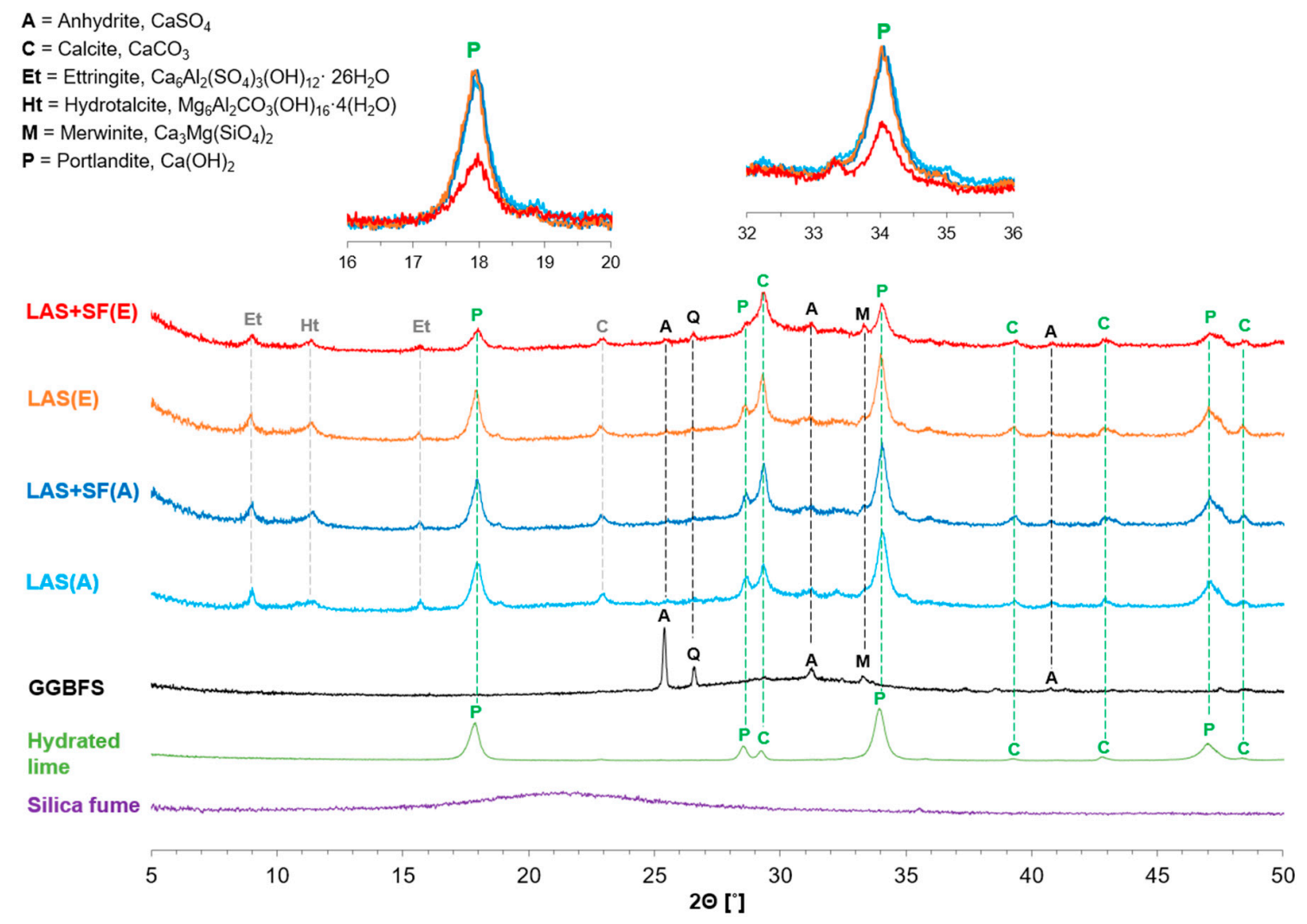

Figure 6. X-ray diffraction (XRD) patterns of paste samples at 28 days (black-, green-, and grey-dashed lines indicate the peaks induced by GGBFS, hydrated lime (HL), and newly formed crystalline phases, respectively).

\subsubsection{Pore Structure Analysis}

Figure 7 shows the pore size distribution of the slag mortars at 91 days. In terms of the reduction in total porosity, the addition of SF was effective regardless of the curing conditions, while the elevated temperature curing was only effective when SF was included. Furthermore, the evidence of the pore filling effect by SF is found in the figure. In the case of ambient curing, the volume of the pores corresponding to the size of SF is considerably lower in LAS + SF(A) than in LAS(A). This is due to the pore filling effect by SF, which fills the large capillary pores $(50 \mathrm{~nm}-1 \mu \mathrm{m})$ [41,42]. As a result, the volume of the capillary pores, smaller than the size of SF (i.e., 10-30 nm), increased. However, the filling effect was not clearly observed in the mortars with elevated temperature curing. Moreover, the volume of the pores between 4-30 nm, not between 30-50 nm, decreased. A promising reason for such an inconsistent change in the pore structure is the cross-over effect, which will be discussed in the next paragraph.

Another notable finding is the peak formed between 600-1000 nm, which occurred only in LAS(E) among all samples. This could have affected the long-term strength after 28 days negatively, as shown in Figure 3, because capillary pores larger than $50 \mathrm{~nm}$ have the primary effect on strength [25]. Similar results (i.e., loss in long-term strength, due to elevated temperature curing) have been reported in alkali-activated slag composites [43]. In addition to this, the long-term strength could have been affected by the cross-over effect $[44,45]$. If the hydration rate is too fast to have enough time to uniformly distribute the produced hydration products around the slag particles, the pore structure is unevenly distributed, causing the formation of large capillary pores that can potentially reduce 
the long-term strength and elastic modulus [17,43]. Hence, the cross-over effect can also explain the reason behind that elevated temperature curing was hardly effective in improving the elastic modulus, as mentioned in Section 3.1. Furthermore, the current study additionally reports that undesirable results in long-term strength, due to initial elevated temperature curing, can be mitigated by adding SF; indeed, the mechanical properties are remarkably improved due to the intensified pozzolanic reaction.


Figure 7. Pore size distribution of slag mortars at 91 days: (a) Ambient curing and (b) elevated temperature curing.

\subsection{Shrinkage and Weight Loss}

The shrinkage behaviors of the LAS mortars with or without SF are shown in Figure 8. Under the ambient curing condition, autogenous shrinkage steadily proceeded for 91 days (Figure 8a) and, in turn, occupied almost half of the total shrinkage at 91 days (Figure 9). This means that both self-desiccation and water evaporation concurrently occurred unless sealed and that autogenous shrinkage is an important component of the total shrinkage of the developed slag mortars. In general, autogenous shrinkage occurs in a paste with a low $\mathrm{w} / \mathrm{b}$, because of the self-desiccation in the capillary pores, which is caused by the water-consuming hydration reaction $[46,47]$. The continuously increased hydration heat shown in Figure 5b, demonstrates that the slag reaction and/or pozzolanic reaction was valid in the LAS mortars. Furthermore, the strength development of the ambient-cured samples implies a steady hydration reaction for 91 days (Figure 3). However, the autogenous shrinkage decreased due to the SF addition at the ambient curing condition. This can be explained by the disturbed slag reaction as presented in Figure 5b.
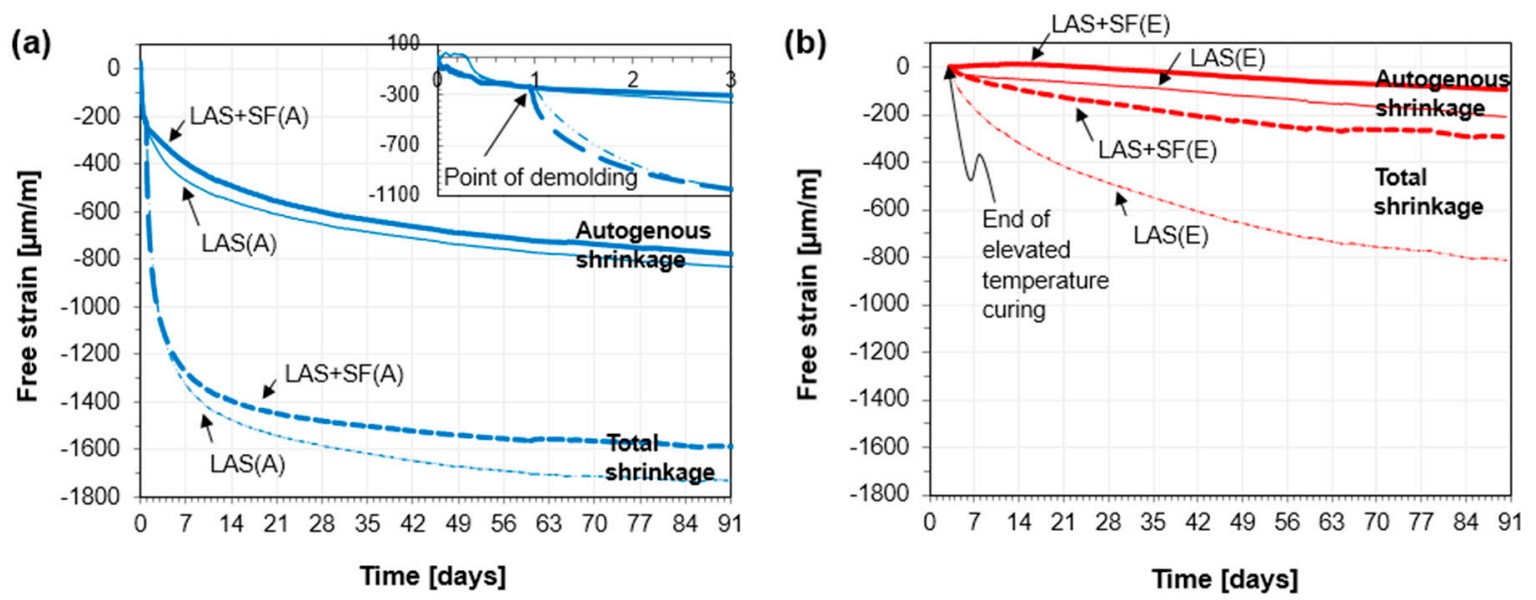

Figure 8. Shrinkage of slag mortars for 91 days: (a) Ambient curing and (b) elevated temperature curing. 
Previously, a low w/b (0.3) slag paste activated by PC (GGBFS:PC $=85 \%: 15 \%$ ) also continued to shrink under a sealed condition, at least for 28 days [48]. The long-term hydration reaction in a low $\mathrm{w} / \mathrm{b}$ system consumes internal moisture continually while making the microstructure denser, which contributes to the increase in the autogenous shrinkage $[48,49]$. For this reason, both previous and current studies have consistently shown the occurrence of long-term autogenous shrinkage in the GGBFS-based composites. However, unlike the LAS system, the shrinkage of the PC-activated slag started after five days; this is attributed to a late activation of the slag [48]. In other words, the insufficient amount of $\mathrm{Ca}(\mathrm{OH})_{2}$, to activate slag reaction, is generated as a result of the cement hydration in PC based slag system. In the LAS system, on the other hand, high amount of $\mathrm{Ca}(\mathrm{OH})_{2}$ is initially provided. This results in the instantaneous shrinkage (Figure 8a). This comparison suggests that $\mathrm{Ca}(\mathrm{OH})_{2}$ has an important role in the autogenous shrinkage of GGBFS-based composites.

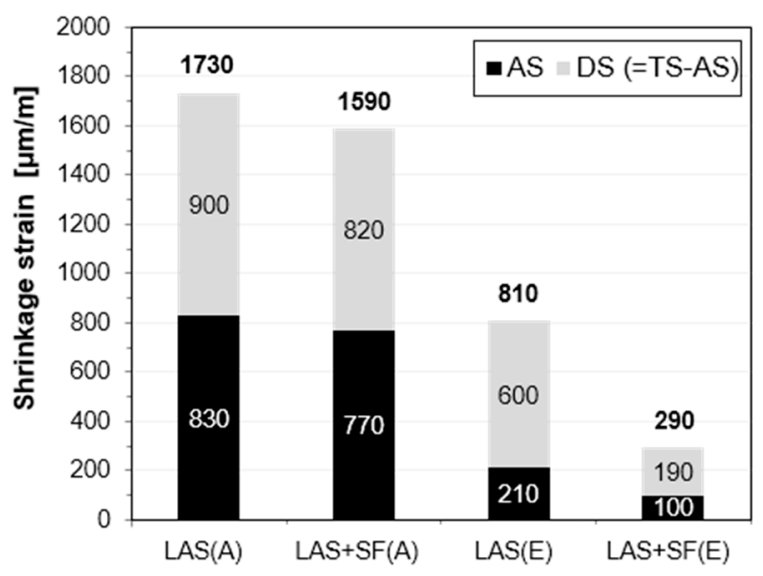

Figure 9. The magnitude of shrinkage deformation at 91 days due to autogenous (AS), drying (DS), and total shrinkage (TS).

It is well known that drying shrinkage in concrete or mortar is caused by water evaporation $[50,51]$. As soon as the seal was removed on the next day of casting, the total shrinkage (or drying shrinkage) proceeded very rapidly for about one week (Figure 8a). This can be clearly explained by weight change, as shown in Figure 10, in which weight loss due to evaporation is exceptionally significant for the first week. The figure also provides the reason why the total shrinkage is lower in LAS + SF(A) than in LAS(A). SF particles adsorb water in the mortar [52], and thus driving force for the drying shrinkage is reduced [50]. Consequently, the decrease in water evaporation, due to SF addition, as well as the reduction in autogenous shrinkage, contributed to a decrease in the total shrinkage.

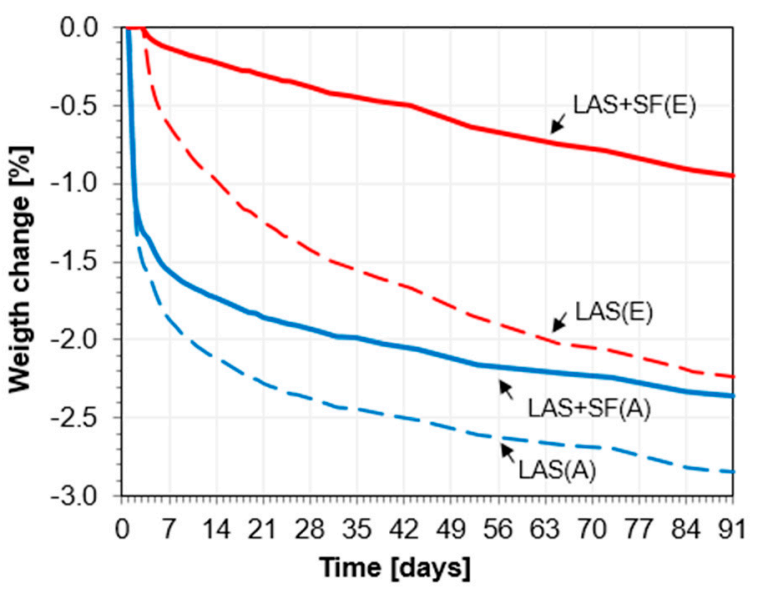

Figure 10. Weight loss of slag mortars for 91 days. 
The shrinkage behavior after elevated temperature curing is presented in Figure $8 \mathrm{~b}$. The amount of autogenous shrinkage between three and 91 days was considerably small, as compared to the case without the elevated temperature curing. This can be explained by the accelerated slag and/or pozzolanic reaction during the first three days, as indicated in Figure 5. During this period, a considerable amount of water in the capillaries is expected to be consumed for the slag and/or pozzolanic reaction. Thus, weight loss after three days should be significantly low, as compared to the case of ambient curing. This is, indeed, confirmed in LAS $+\mathrm{SF}(\mathrm{E})$, as its drying shrinkage and weight loss at 91 days were especially small among all samples. However, those of LAS(E) are significantly large; in other words, the drying shrinkage and weight loss are three times and two times than LAS + SF(E), respectively. This again indicates that the pozzolanic reaction, which consumes HL and water, was promoted due to the addition of SF. Although the causes are different, the addition of SF contributed to reducing both autogenous and total shrinkages of LAS mortars with or without elevated temperature curing.

\section{Conclusions}

In an effort to reduce the consumption of PC, this study investigated the influence of the pore filling effect and the intensified pozzolanic reaction by SF on various material properties of LAS mortar. The addition of SF was highly effective to improve the mechanical properties of the slag mortar. Without an elevated temperature curing, compressive strength, elastic modulus and flexural strength increased by $25 \%, 34 \%$, and $18 \%$ at 91 days, respectively. As a result, the mortar with SF showed $>40 \mathrm{MPa}$ after 14 days at a room temperature of $20^{\circ} \mathrm{C}$. The hydration reaction and microstructural analysis confirmed the physical contribution of the ultrafine SF particles, which is explained by the pore filling effect. Due to this, the volume of large capillary pores, which is closely related to mechanical properties, decreased. At an elevated temperature of $60^{\circ} \mathrm{C}$, the SF addition promoted the pozzolanic reaction of the mortar. This not only increased compressive strength, but also accelerated the strength development. For this reason, a high strength of about $60 \mathrm{MPa}$ could be achieved after three days. In addition, the LAS mortar showed both autogenous shrinkage and drying shrinkage gradually increased up to 91 days. However, the addition of SF was effective in improving dimensional stability of the slag mortar, regardless of the curing conditions.

Author Contributions: Y.-H.K. and S.-H.K. conducted experiments, analyzed the test results, and wrote the manuscript. S.-G.H. and J.M. advised on the design of the experiments, the analysis, and the interpretation of the results, and manuscript revision.

Funding: This research was supported by Basic Science Research Program through the National Research Foundation of Korea (NRF) funded by the Ministry of Education (NRF-018R1C1B5040859).

Acknowledgments: The Institute of Engineering Research in Seoul National University provided research facilities for this work.

Conflicts of Interest: The authors declare no conflict of interest.

\section{References}

1. Intergovernmental Panel on Climate Change (IPCC). Special Report on Global Warming of $1.5^{\circ} \mathrm{C}$ : Summary for Policymakers; IPCC: Incheon, Korea, 2018; pp. 1-33.

2. Ye, H.; Radlińska, A. Shrinkage mechanisms of alkali-activated slag. Cem. Concr. Res. 2016, 88, 126-135. [CrossRef]

3. Miller, S.A. Supplementary cementitious materials to mitigate greenhouse gas emissions from concrete: Can there be too much of a good thing? J. Clean. Prod. 2018. [CrossRef]

4. Monteiro, P.J.M.; Miller, S.A.; Horvath, A. Towards sustainable concrete. Nat. Mater. 2017, 16, 698. [CrossRef] [PubMed]

5. Zhao, H.; Sun, W.; Wu, X.; Gao, B. The properties of the self-compacting concrete with fly ash and ground granulated blast furnace slag mineral admixtures. J. Clean. Prod. 2015, 95, 66-74. [CrossRef] 
6. Rashad, A.M. An investigation of high-volume fly ash concrete blended with slag subjected to elevated temperatures. J. Clean. Prod. 2015, 93, 47-55. [CrossRef]

7. Mo, K.H.; Johnson Alengaram, U.; Jumaat, M.Z.; Yap, S.P. Feasibility study of high volume slag as cement replacement for sustainable structural lightweight oil palm shell concrete. J. Clean. Prod. 2015, 91, 297-304. [CrossRef]

8. Provis, J.L.; Bernal, S.A. Geopolymers and related alkali-activated materials. Annu. Rev. Mater. Res. 2014, 44, 299-327. [CrossRef]

9. Bontempi, E. A new approach for evaluating the sustainability of raw materials substitution based on embodied energy and the $\mathrm{CO}_{2}$ footprint. J. Clean. Prod. 2017, 162, 162-169. [CrossRef]

10. Bontempi, E. A new approach to evaluate the sustainability of raw materials substitution. In Raw Materials Substitution Sustainability; Springer: Cham, Switzerland, 2017; pp. 79-101.

11. Jeong, Y.; Park, H.; Jun, Y.; Jeong, J.H.; Oh, J.E. Influence of slag characteristics on strength development and reaction products in a CaO-activated slag system. Cem. Concr. Compos. 2016, 72, 155-167. [CrossRef]

12. Melo Neto, A.A.; Cincotto, M.A.; Repette, W. Drying and autogenous shrinkage of pastes and mortars with activated slag cement. Cem. Concr. Res. 2008, 38, 565-574. [CrossRef]

13. Bilim, C.; Karahan, O.; Atiş, C.D.; İlkentapar, S. Influence of admixtures on the properties of alkali-activated slag mortars subjected to different curing conditions. Mater. Des. 2013, 44, 540-547. [CrossRef]

14. Puertas, F.; Martínez-Ramírez, S.; Alonso, S.; Vázquez, T. Alkali-activated fly ash/slag cements: Strength behaviour and hydration products. Cem. Concr. Res. 2000, 30, 1625-1632. [CrossRef]

15. Wang, J.; Lyu, X.; Wang, L.; Cao, X.; Liu, Q.; Zang, H. Influence of the combination of calcium oxide and sodium carbonate on the hydration reactivity of alkali-activated slag binders. J. Clean. Prod. 2018, 171, 622-629. [CrossRef]

16. Gruskovnjak, A.; Lothenbach, B.; Holzer, L.; Figi, R.; Winnefeld, F. Hydration of alkali-activated slag: Comparison with ordinary Portland cement. Adv. Cem. Res. 2006, 18, 119-128. [CrossRef]

17. Fernández-Jiménez, A.; Palomo, J.G.; Puertas, F. Alkali-activated slag mortars: Mechanical strength behaviour. Cem. Concr. Res. 1999, 29, 1313-1321. [CrossRef]

18. Kim, M.S.; Jun, Y.; Lee, C.; Oh, J.E. Use of $\mathrm{CaO}$ as an activator for producing a price-competitive non-cement structural binder using ground granulated blast furnace slag. Cem. Concr. Res. 2013, 54, 208-214. [CrossRef]

19. Yang, K.-H.; Cho, A.-R.; Song, J.-K.; Nam, S.-H. Hydration products and strength development of calcium hydroxide-based alkali-activated slag mortars. Constr. Build. Mater. 2012, 29, 410-419. [CrossRef]

20. Burciaga-Díaz, O.; Betancourt-Castillo, I. Characterization of novel blast-furnace slag cement pastes and mortars activated with a reactive mixture of MgO-NaOH. Cem. Concr. Res. 2018, 105, 54-63. [CrossRef]

21. Arellano-Aguilar, R.; Burciaga-Díaz, O.; Gorokhovsky, A.; Escalante-García, J.I. Geopolymer mortars based on a low grade metakaolin: Effects of the chemical composition, temperature and aggregate:binder ratio. Constr. Build. Mater. 2014, 50, 642-648. [CrossRef]

22. Thomas, R.J.; Lezama, D.; Peethamparan, S. On drying shrinkage in alkali-activated concrete: Improving dimensional stability by aging or heat-curing. Cem. Concr. Res. 2017, 91, 13-23. [CrossRef]

23. Pfeifer, C.; Moeser, B.; Weber, C.; Stark, J. Investigations of the Pozzolanic Reaction of Silica Fume in Ultra-High Performance Concrete (UHPC). In Proceedings of the International RILEM Conference on Material Science-MATSCI, Aachen, Germany, 6-8 September 2010; pp. 287-298.

24. Kang, S.-H.; Lee, J.-H.; Hong, S.-G.; Moon, J. Microstructural investigation of heat-treated ultra-high performance concrete for optimum production. Materials 2017, 10, 1106. [CrossRef] [PubMed]

25. Mehta, P.K.; Monteiro, P.J. Concrete-Microstructure, Properties and Materials; McGeaw-Hill: New York, NY, USA, 2006.

26. Kwon, Y.-H.; Kang, S.-H.; Hong, S.-G.; Moon, J. Acceleration of intended pozzolanic reaction under initial thermal treatment for developing cementless fly ash based mortar. Materials 2017, 10, 225. [CrossRef] [PubMed]

27. Kwon, Y.-H.; Kang, S.-H.; Hong, S.-G.; Moon, J. Intensified pozzolanic reaction on kaolinite clay-based mortar. Appl. Sci. 2017, 7, 522. [CrossRef]

28. ISO 679, Cement-Test Methods-Determination of Strength; International Organization for Standardization: Geneva, Switzerland, 2009; p. 29. 
29. Thorstensen, R.T.; Fidjestol, P. Inconsistencies in the pozzolanic strength activity index (SAI) for silica fume according to EN and ASTM. Mater. Struct. 2015, 48, 3979-3990. [CrossRef]

30. Astm C305-14, Standard Practice for Mechanical Mixing of Hydraulic Cement Pastes and Mortars of Plastic Consistency; ASTM International: West Conshohocken, PA, USA, 2014; p. 3.

31. ASTM C109/C109M-16a, Standard Test Method for Compressive Strength of Hydraulic Cement Mortars (Using 2-in. or [50-mm] Cube Specimens); ASTM International: West Conshohocken, PA, USA, 2016; p. 10.

32. Kang, S.-H.; Hong, S.-G.; Moon, J. Shrinkage characteristics of heat-treated ultra-high performance concrete and its mitigation using superabsorbent polymer based internal curing method. Cem. Concr. Compos. 2018, 89, 130-138. [CrossRef]

33. Belsky, A.; Hellenbrandt, M.; Karen, V.L.; Luksch, P. New developments in the Inorganic Crystal Structure Database (ICSD): Accessibility in support of materials research and design. Acta Crystallogr. B Struct. Cryst. Cryst. Chem. 2002, 58 Pt 1, 364-369. [CrossRef]

34. Kang, S.-H.; Hong, S.-G.; Moon, J. Importance of drying to control internal curing effects on field casting ultra-high performance concrete. Cem. Concr. Res. 2018, 108, 20-30. [CrossRef]

35. Zhang, M.; Tam, C.; Leow, M. Effect of water-to-cementitious materials ratio and silica fume on the autogenous shrinkage of concrete. Cem. Concr. Res. 2003, 33, 1687-1694. [CrossRef]

36. Yogendran, V.; Langan, B.W.; Ward, M.A. Hydration of cement and silica fume paste. Cem. Concr. Res. 1991, 21, 691-708. [CrossRef]

37. Langan, B.W.; Weng, K.; Ward, M.A. Effect of silica fume and fly ash on heat of hydration of Portland cement. Cem. Concr. Res. 2002, 32, 1045-1051. [CrossRef]

38. Chatterji, S.; Thaulow, N.; Christensen, P. Puzzolanic activity of byproduct silica-fume from ferro-silicom production. Cem. Concr. Res. 1982, 12, 781-784. [CrossRef]

39. Gameiro, A.; Santos Silva, A.; Faria, P.; Grilo, J.; Branco, T.; Veiga, R.; Velosa, A. Physical and chemical assessment of lime-metakaolin mortars: Influence of binder:aggregate ratio. Cem. Concr. Compos. 2014, 45, 264-271. [CrossRef]

40. Fernández, J.M.; Duran, A.; Navarro-Blasco, I.; Lanas, J.; Sirera, R.; Alvarez, J.I. Influence of nanosilica and a polycarboxylate ether superplasticizer on the performance of lime mortars. Cem. Concr. Res. 2013, 43, 12-24. [CrossRef]

41. Kang, S.-H.; Hong, S.-G.; Moon, J. The effect of superabsorbent polymer on various scale of pore structure in ultra-high performance concrete. Constr. Build. Mater. 2018, 172, 29-40. [CrossRef]

42. Kang, S.-H.; Jeong, Y.; Tan, K.H.; Moon, J. The use of limestone to replace physical filler of quartz powder in UHPFRC. Cem. Concr. Compos. 2018, 94, 238-247. [CrossRef]

43. Bakharev, T.; Sanjayan, J.G.; Cheng, Y.B. Effect of elevated temperature curing on properties of alkali-activated slag concrete. Cem. Concr. Res. 1999, 29, 1619-1625. [CrossRef]

44. Çakır, Ö.; Aköz, F. Effect of curing conditions on the mortars with and without GGBFS. Constr. Build. Mater. 2008, 22, 308-314. [CrossRef]

45. Castellano, C.C.; Bonavetti, V.L.; Donza, H.A.; Irassar, E.F. The effect of $\mathrm{w} / \mathrm{b}$ and temperature on the hydration and strength of blastfurnace slag cements. Constr. Build. Mater. 2016, 111, 679-688. [CrossRef]

46. Jensen, O.M.; Hansen, P.F. Autogenous deformation and change of the relative humidity in silica fume-modified cement paste. ACI Mater. J. 1996, 93, 539-543.

47. Lura, P.; Jensen, O.M.; van Breugel, K. Autogenous shrinkage in high-performance cement paste: An evaluation of basic mechanisms. Cem. Concr. Res. 2003, 33, 223-232. [CrossRef]

48. Snoeck, D.; Jensen, O.M.; De Belie, N. The influence of superabsorbent polymers on the autogenous shrinkage properties of cement pastes with supplementary cementitious materials. Cem. Concr. Res. 2015, 74, 59-67. [CrossRef]

49. Lura, P.; van Breugel, K.; Maruyama, I. Effect of curing temperature and type of cement on early-age shrinkage of high-performance concrete. Cem. Concr. Res. 2001, 31, 1867-1872. [CrossRef]

50. Zhang, W.; Hama, Y.; Na, S.H. Drying shrinkage and microstructure characteristics of mortar incorporating ground granulated blast furnace slag and shrinkage reducing admixture. Constr. Build. Mater. 2015, 93, 267-277. [CrossRef] 
51. Bissonnette, B.; Pierre, P.; Pigeon, M. Influence of key parameters on drying shrinkage of cementitious materials. Cem. Concr. Res. 1999, 29, 1655-1662. [CrossRef]

52. Mechtcherine, V.; Secrieru, E.; Schröfl, C. Effect of superabsorbent polymers (SAPs) on rheological properties of fresh cement-based mortars-Development of yield stress and plastic viscosity over time. Cem. Concr. Res. 2015, 67, 52-65. [CrossRef] 